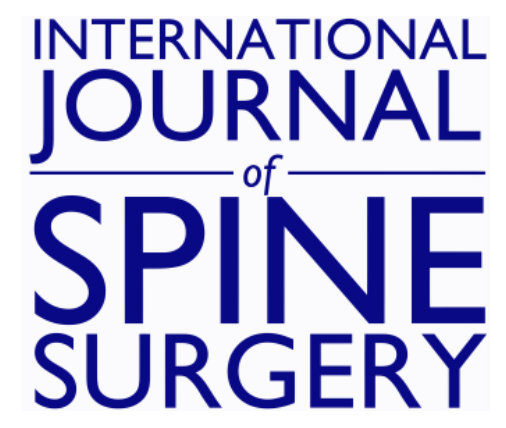

\title{
Assessment of Magnetic Resonance Imaging Artifact Following Cervical Total Disc Arthroplasty
}

Amir H. Fayyazi, Jennifer Taormina, David Svach, Jeff Stein and Nathaniel R. Ordway

Int J Spine Surg 2015, 9 ()

doi: https://doi.org/10.14444/2030

http://ijssurgery.com/content/9/30

This information is current as of April 26, 2023.

Email Alerts Receive free email-alerts when new articles cite this article. Sign up at:

http://ijssurgery.com/alerts

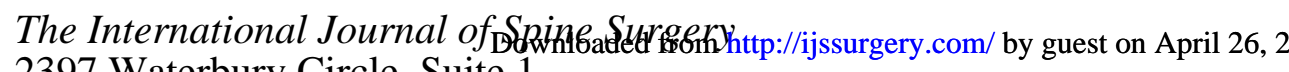
2397 Waterbury Circle, Suite 1,

Aurora, IL 60504, Phone: +1-630-375-1432

(C) 2015 ISASS. All Rights Reserved. 


\section{Assessment of Magnetic Resonance Imaging Artifact Following Cervical Total Disc Arthroplasty}

Amir H. Fayyazi, MD, ${ }^{1}$ Jennifer Taormina, MS, ${ }^{2}$ David Svach, $M S,{ }^{3}$ Jeff Stein, PhD, ${ }^{4}$ Nathaniel R. Ordway, MS ${ }^{2}$

${ }^{1} O A A$ Orthopaedic Specialists, Allentown, PA, ${ }^{2} S U N Y$ Upstate Medical University, Syracuse, NY, ${ }^{3}$ Research \& Testing, Depuy Synthes, West Chester, $P A,{ }^{4}$ Clinical Biostatistics \& Data Management, DePuy Synthes, West Chester, PA

\section{Abstract}

Background

Cervical disc arthroplasty has become a technique for the treatment of cervical degenerative disc disease. Clinically, the need to accurately assess the neural elements at the operative and adjacent levels is critical postoperatively. The purpose of this study was to quantitatively and qualitatively measure the amount of MRI artifact produced by various cervical total disc replacements.

\section{Methods}

T1 and T2-weighted turbo spin-echo MRI sequences were collected on the cervical spine (C2-T1) of a 68 year-old unembalmed male cadaver. A discectomy was performed at C5-6, followed by successive implantation of six different total disc replacements. The scans were quantitatively evaluated by three of the authors. The volume of artifact was measured using image analysis software. Qualitative analysis of the adjacent and index neural elements was performed.

Results

The artifact in the T2 weighted images was noted to be $58.6 \pm 7.3 \mathrm{~cm} 3$ for Prestige ST, $14.2 \pm 1.3 \mathrm{~cm} 3$ for ProDisc-C, $7.5 \pm 0.8 \mathrm{~cm} 3$ for Discover, $8.0 \pm 0.3 \mathrm{~cm} 3$ for Prestige LP, $6.6 \pm 0.7 \mathrm{~cm} 3$ for Bryan, and $7.3 \pm 0.6 \mathrm{~cm} 3$ for ProDisc-C titanium prototype. Acceptable intraobserver and excellent interobsever correlation was demonstrated using Pearson Correlation and Concordance Correlation Coefficient analysis. The adjacent and implanted level neural elements (spinal cord and neuroforamina) were easily visualized on the T2 weighted images after the implantation of titanium devices (ProDisc-C titanium prototype, Discover, Prestige LP and Bryan). After implantation of a cobalt chrome implant (ProDisc-C), the adjacent level neural elements were easily visualized but the implanted level could not be fully visualized due to distortion of the images. The quality of the distortion was least favorable after the implantation of the stainless steel implant (Prestige ST), where neither the adjacent nor the index level could be fully visualized.

\section{Conclusion}

The volume of the artifact seen following cervical total disc arthroplasty is highly dependent upon the material property of the implant. Quantitative analysis described in this study demonstrated sufficiently low intraobserver and interobserver variability to be considered a reliable technique.

keyWords: Cervical Spine, Total disc arthroplasty, MRI, Artifact, Quantitative Measurement, Qualitative Measurement VOLUME 9 ARTICLE 30 DOI: 10.14444/2030

\section{Introduction}

Cervical disc arthroplasty has the potential to become a widespread technique used for the treatment of cervical degenerative disc disease. One of the drawbacks associated with these implants is difficulty in postoperative Magnetic Resonance Imaging (MRI) evaluation of the cervical spine. Distortion of the magnetic field by metallic implants can cause poor Downloaded from http://ijssurgery.com/ by guest on April 26, 2023 image quality and make it difficult to assess boney and neurologic structures at the implanted and adjacent levels. The need to accurately assess the neural elements at the operative level and adjacent levels is critical postoperatively and can be challenging given the difficulty associated with imaging of metallic implants. ${ }^{1}$

There are many different cervical disc replacements, 
which vary in both design and construct materials, that are currently being used and investigated. The most commonly used metallic materials are stainless steel, cobalt chrome, and titanium alloys. ${ }^{2,3}$ It has been shown that spinal devices made of titanium can produce higher quality magnetic resonance images than other materials. ${ }^{4,5}$ However considering the variety of cervical disc replacement devices (both geometry and materials), ${ }^{3}$ postoperative MRI evaluation of the neural elements can be difficult especially in cases where cobalt chrome or stainless steel implants have been implanted.

There have been attempts to improve the quality of MRI images adjacent to a metallic implant. Many studies have demonstrated ways to minimize the artifact associated with metallic implants. These include using fast spin-echo sequences, adjusting the hardware orientation, reducing the field of view, imaging thinner sections, increasing echo train length, and increasing receiver bandwidth..$^{6-8}$ A more advanced technique, tilted view angle sequences have been shown to reduce image artifact, but can result in blurring and field of view shift. ${ }^{8}$ These specialty techniques also may be impractical to implement, particularly on older MR scanners and beyond the knowledge of some MR operators.

Using routine MR sequences, Sekhon et. al. qualitatively examined four different cervical disc replacements in twenty different patients. ${ }^{1}$ They concluded that visualization of structures surrounding a titanium cervical disc was excellent whereas visualization of structures surrounding a cobalt-chrome device was poor.

The purpose of this study was to quantitatively and qualitatively measure the MRI artifact produced by cervical total disc replacements made from different materials for both $\mathrm{T} 1$ and $\mathrm{T} 2$-weighted images in a human cadaveric model and to evaluate the interobservor and the intraobserver reliability of the measurement technique.

\section{Material And Methods}

Cadaveric Specimen

A 68 year-old unembalmed full-body male cadaver was acquired for use in this study. Prior to starting, the specimen was radiographically screened to confirm that total cervical disc arthroplasty could be performed. There was no evidence of bony abnormalities or severe disc degeneration that would prevent the implantation of a total disc replacement.

\section{MR Scanning of Intact Spine}

A baseline MRI of the intact cervical spine (C2-T1) was obtained using a Philips Intera 1.5 Tesla whole body MRI scanner (Philips Medical Systems, Andover, MA) with a synergy spine coil. Turbo spin echo $\mathrm{T} 1$ and $\mathrm{T} 2$ sequences (Table 1 ) were obtained in the sagittal and axial planes using a $3 \mathrm{~mm}$ slice thickness. For T1 and T2 sagittal sequences, TR values of $400 \mathrm{~ms}$ and $3500 \mathrm{~ms}$ and $\mathrm{TE}$ values of $7.4 \mathrm{~ms}$ and $120 \mathrm{~ms}$ were used, respectively. For T1 and T2 axial sequences, TR values of $1089 \mathrm{~ms}$ and $3500 \mathrm{~ms}$ and TE values of $7.8 \mathrm{~ms}$ and $80 \mathrm{~ms}$ were used, respectively.

\section{Surgical Procedure}

Following the scans of the intact spine, an anterior cervical discectomy was performed in a routine fashion at C5-6 through a right-sided Smith-Robinson approach. The entire disc was removed and the posterior longitudinal ligament was released. Six cervical disc replacement devices were implanted in the following sequence; ProDisc-C (Depuy Synthes, Raynham, MA), ProDisc-C Ti (titanium prototype), Prestige LP (Medtronic Sofamor Danek, Memphis, TN), Discover (Depuy Synthes, Raynham, MA), Bryan (Medtronic Sofamor Danek), and Prestige ST (Medtronic Sofamor Danek) (Table 2). MRI scanning of the instrumented cervical spine was repeated after implantation of each of these devices, using the same sequences as that described above for the intact spine (Table 1).

Quantitative Analysis

The quantity of the artifact was measured using im-

\begin{tabular}{|c|c|c|}
\hline & T1 & T2 \\
\hline Sagittal & $\begin{array}{l}\text { TR: } 400 \mathrm{~ms} \\
\text { TE: } 7.4 \mathrm{~ms}\end{array}$ & $\begin{array}{r}\text { TR: } 3500 \mathrm{~ms} \\
\text { TE: } 120 \mathrm{~ms}\end{array}$ \\
\hline Axial & $\begin{array}{r}\text { TR: } 1089 \mathrm{~ms} \\
\text { TE: } 7.8 \mathrm{~ms}\end{array}$ & $\begin{array}{r}\text { TR: } 3500 \mathrm{~ms} \\
\text { TE: } 80 \mathrm{~ms}\end{array}$ \\
\hline
\end{tabular}

Downloaded from http://ijssurgery.com/ by guest on April 26, 2023 
age analysis software (eFilm Lite v1.8.3, eFilm Medical, Inc., Toronto, ON). The area of the artifact was measured on each axial slice by three of the authors on two different occasions separated by more than three months. In short, each axial slice from an implanted scan was compared side-by-side to a similar slice from the baseline scan (with no artifact), and an elliptical region of interest (ROI) was drawn around the observed artifact with major and minor diameters of the ellipse bounding the outskirts of the artifact (Figure 1). An elliptical ROI was used because a distinct boundary of the artifact was difficult to determine and the elliptical ROI represents a conservative measurement of the artifact. The area of artifact us-

Table 2. List of cervical implants imaged as well as the size and weight ranges.

\begin{tabular}{|c|c|c|c|c|}
\hline & Implant Materials & $\begin{array}{l}\text { Size Used } \\
(\mathrm{mm})(\text { deep } \\
\mathrm{x} \text { width } \mathrm{x} \\
\text { height) }\end{array}$ & $\begin{array}{l}\text { Size } \\
\text { Range } \\
(\mathbf{m m})\end{array}$ & $\begin{array}{l}\text { Weight } \\
\text { Range } \\
\text { (grams) }\end{array}$ \\
\hline Prodisc-C & $\begin{array}{l}\text { CoCrMo endplates with } \\
\text { plasma-sprayed titanium } \\
\text { surface, UHMWPE inlay }\end{array}$ & $12 \times 15 \times 5$ & $\begin{array}{l}12- \\
18 \mathrm{D} \\
15- \\
19 \mathrm{~W} \\
5-7 \\
\mathrm{H}\end{array}$ & $\begin{array}{l}4.43- \\
9.26\end{array}$ \\
\hline $\begin{array}{l}\text { Prodisc-C } \\
\text { Ti } \\
\text { (prototype) }\end{array}$ & $\begin{array}{l}\text { TAN Endplates, superior } \\
\text { CoCrMo insert, inferior } \\
\text { UHMWPE inlay }\end{array}$ & $12 \times 15 \times 5$ & $\begin{array}{l}12- \\
18 \mathrm{D} \\
15- \\
19 \mathrm{~W} \\
5-7 \\
\mathrm{H}\end{array}$ & $\begin{array}{l}2.73- \\
5.64\end{array}$ \\
\hline $\begin{array}{l}\text { Prestige } \\
\text { LP }\end{array}$ & $\begin{array}{l}\text { Titanium Alloy/Titanium } \\
\text { Carbide Composite, } \\
\text { plasma-sprayed titanium } \\
\text { coating }\end{array}$ & $12 \times 17.8 \times 6$ & $\begin{array}{l}12- \\
18 \mathrm{D} \\
17.8 \\
\mathrm{~W} \\
6-8 \\
\mathrm{H}\end{array}$ & $\begin{array}{l}3.65- \\
7.67\end{array}$ \\
\hline Discover & $\begin{array}{l}\text { Titanium Alloy Endplates, } \\
\text { Polyethylene Core }\end{array}$ & $\begin{array}{l}15.2 \times 18.7 \times \\
8\end{array}$ & $\begin{array}{l}13.7- \\
16.7 \mathrm{D} \\
14.2- \\
18.7 \\
\mathrm{~W} \\
5-9 \\
\mathrm{H}\end{array}$ & $\begin{array}{l}2.14- \\
5.54\end{array}$ \\
\hline Bryan & $\begin{array}{l}\text { Titanium shells, } \\
\text { Polyurethane nucleus and } \\
\text { sheath }\end{array}$ & $\begin{array}{l}14 \text { (diameter) } \\
\text { x } 6\end{array}$ & $\begin{array}{l}14- \\
18 \mathrm{D} \\
6 \mathrm{H}\end{array}$ & \\
\hline $\begin{array}{l}\text { Prestige } \\
\text { ST }\end{array}$ & Stainless steel & $14 \times 17.8 \times 7$ & $\begin{array}{l}12- \\
18 \mathrm{D} \\
17.8 \\
\mathrm{~W} \\
6-7 \\
\mathrm{H}\end{array}$ & $\begin{array}{l}10.41- \\
14.74\end{array}$ \\
\hline
\end{tabular}

ing this ROI was calculated. The volume of the artifact was then calculated by multiplying the artifact area from each slice by the thickness of each slice $(3 \mathrm{~mm})$ and summed over the number of slices involved.

\section{Qualitative Analysis}

The quality of the artifact produced following implantation of these devices was examined. In each case, the implanted and the adjacent levels were assessed using the classification described in Table 3. Each level was assessed in both the sagittal and the axial plane. The level was categorized asVisualized if the canal and the bilateral neural foramina were not affected by the artifact. The levels where the neural elements could not be visualized in either the sagittal or the axial planes were categorized as Fully Distort$e d$. And the levels where the neural elements were partially visualized were categorized as level Partially Distorted as demonstrated in Figure 2.

\section{Statistical Analysis}

Statistical analysis was performed using SAS software (SAS Institute Inc, Cary, NC, ver 9.1.3). The total volume of artifact was determined for each implant and for each of the three observers on the initial measurements for the $\mathrm{T} 1$ and $\mathrm{T} 2$ images. $\mathrm{A}$ 1-way ANOVA was performed using the implant type as the main effect for both $\mathrm{T} 1$ and T2. Post hoc

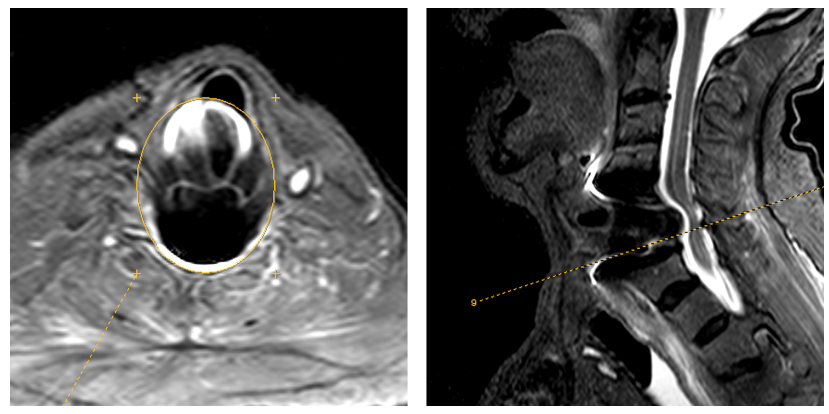

Fig. 1. The area of the artifact was measured on each axial image using eFilm Lite software as demonstrated.

Table 3. Qualitative scoring method used for classifying image artifact.
\begin{tabular}{|l|l|l|}
\hline I & Visualized & $\begin{array}{l}\text { No distinguishable artifact in either sagittal or axial images } \\
\text { of the spinal canal or bilateral neural foramina. }\end{array}$ \\
\hline II & $\begin{array}{l}\text { Partially } \\
\text { Distorted }\end{array}$ & $\begin{array}{l}\text { Distortion of either neural foramina or the spinal canal that } \\
\text { allows partial visualization of the neural structures. }\end{array}$ \\
\hline III & $\begin{array}{l}\text { Fully Dis- } \\
\text { torted }\end{array}$ & $\begin{array}{l}\text { Inability to visualize the neural structures in bilateral neural } \\
\text { foramina and the canal. }\end{array}$ \\
\hline
\end{tabular}


analysis was performed with a Student's t-test to look at differences in artifact volume between implants with a level of significance set at $\alpha=0.05$. Intraobserver Variability was measured using the Pearson Product Moment Correlation Coefficient. Interobserver Variability was measured using Concordance Correlation Coefficient which was computed separately for each time point and for $\mathrm{T} 1$ and $\mathrm{T} 2$ weighted images.

\section{Results}

\section{Quantitative Analysis}

The shape and location of the artifact was highly dependent on the type of the implanted device. Figure 3 graphically illustrates the area of the artifact measured by the observers on each T1 axial image slice following implantation of the six devices. Each axial scanning sequence produced 29 image slices. Of these, up to 24 had measurable artifact present, with slice 1 being the most caudal and slice 24 being most cranial. The artifact was apparent in $23 / 24$ of $\mathrm{T} 1$ and $24 / 24$ of T2 images following the implantation of Prestige ST (Figure 3). Fewer images were affected by artifact following implantation of other devices, as artifact was observed in just $33-42 \%$ and $25-38 \%$ of the images for $\mathrm{T} 1$ and $\mathrm{T} 2$-weighted images, respectively.

Figure 4 demonstrates the volume of the artifact measured following implantation of each device. The volume of the artifact in the T1/T2 weighted images was $70.3 \pm 16.0 / 58.6 \pm 7.3 \mathrm{~cm}^{3}$ for Prestige ST, $15.3 \pm 1.5 / 14.2 \pm 1.3 \mathrm{~cm}^{3}$ for ProDisc-C, $9.4 \pm 0.4$ /
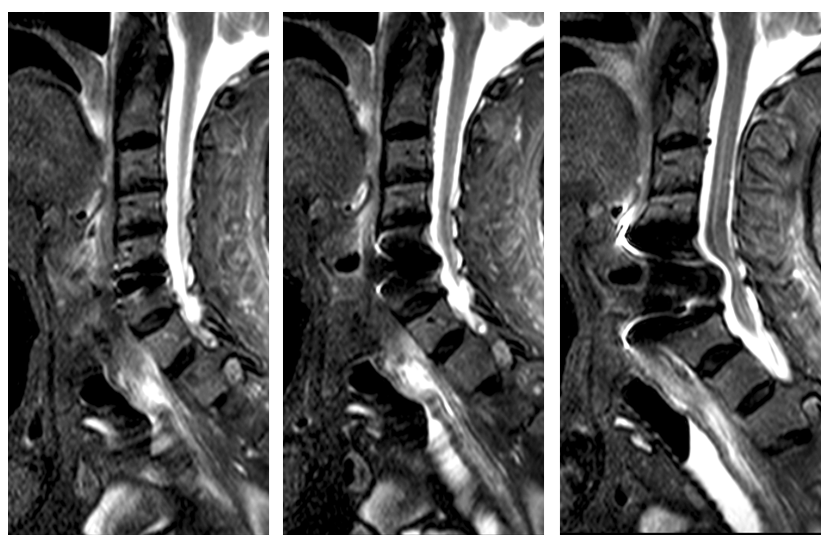

Fig. 2. Corresponding T2 weighted sagittal and axial images of Visualized, Partially Distorted, and Fully Distorted implanted segments.
$7.5 \pm 0.8 \mathrm{~cm}^{3}$ for Discover, $7.7 \pm 1.4 / 8.0 \pm 0.3 \mathrm{~cm}^{3}$ for Prestige LP, $6.8 \pm 1.0$ / $6.6 \pm 0.7 \mathrm{~cm}^{3}$ for Bryan, and $7.4 \pm 1.0 / 7.3 \pm 0.6 \mathrm{~cm}^{3}$ for ProDisc-C Ti implant. The average volume of the artifact was larger on $\mathrm{T} 1 \mathrm{im}$ ages when compared to $\mathrm{T} 2$ images after implantation of the Prestige ST implant, ProDisc-C implant, and the Discover implant. Smaller differences were seen between the sequences with the Bryan, Prestige LP and ProDisc-C Ti implants.

The volume of the artifact measured on $\mathrm{T} 1$ and $\mathrm{T} 2$ sequences was significantly larger $(\mathrm{p}<0.001)$ after implantation of a stainless implant (Prestige ST) compared to other devices. For the T2 sequence, the volume of measured artifact following the implantation of the cobalt-chrome ProDisc-C device was significantly greater $(\mathrm{p}<0.03)$ than the comparable titanium ProDisc-C prototype, as well as the other tita-

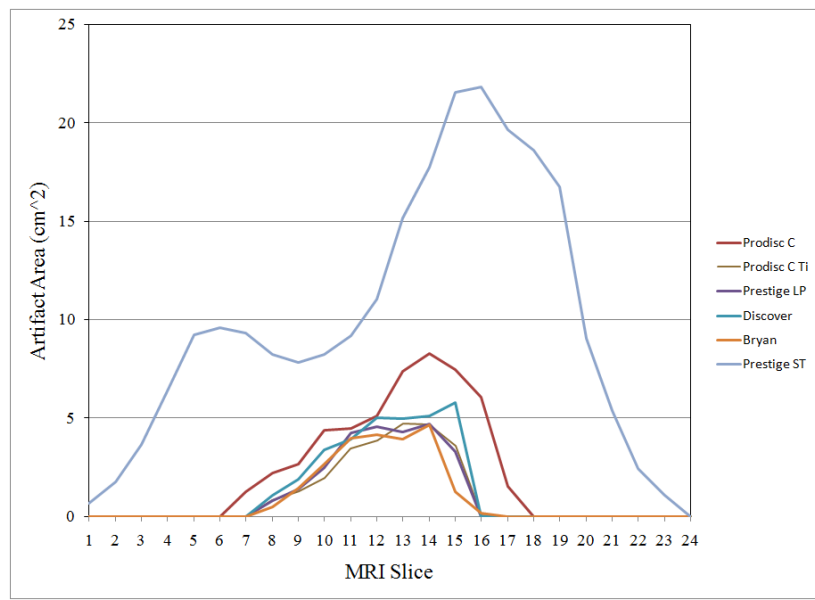

Fig. 3. The cross-sectional area of the artifact measures in each slice was dependent on the shape and material property of the device.

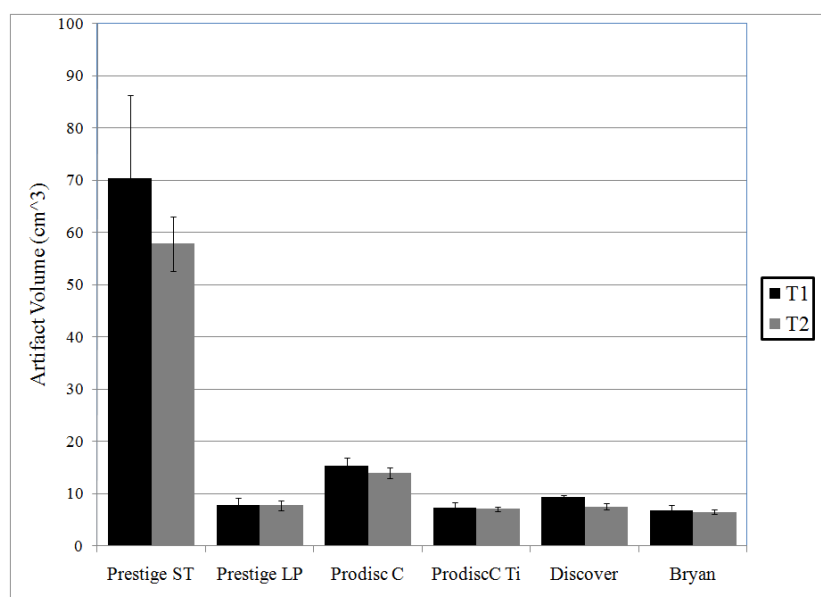

Fig. 4. The volume of the artifact measured was significantly larger following implantation of the Prestige ST implant. 
nium devices. There were no other significant differences in volume of artifact between devices for both $\mathrm{T} 1$ and $\mathrm{T} 2$ sequences.

\section{Intraobserver Analysis}

The Pearson Product Moment Correlation Coefficient was estimated for both the $\mathrm{T} 1$ and $\mathrm{T} 2$ measurements for each observer. The measurements were repeated excluding the Prestige ST data. Overall measurements were also analyzed for each sequence with and without the Prestige ST data. In each case, the Correlation Coefficient was estimated between 0.97 to 1.0 representing almost perfect intraobserver reliability (Table 4).

\section{Interobserver Analysis}

The Concordance Correlation Coefficient was estimated separately for $\mathrm{T} 1$ and $\mathrm{T} 2$ sequences, first and repeat measurement, and with or without Prestige ST. The correlation coefficient in each case was measured between 0.86 and 0.99 (Table 5).

\section{Qualitative Analysis}

In general, the quality of the artifact observed on T2 weighted images was subjectively better than that seen on the T1 weighted images. With the T2 weighted images, there appeared to be less artifact, which in turn made it easier to visualize the neural structures. Minimal artifact (Figure 5) was noted fol-

Table 4. Pearson Product Moment Correlation Coefficients.

\begin{tabular}{|l|r|r|r|r|}
\hline & $\begin{array}{r}\text { TI } \\
\text { (All) }\end{array}$ & $\begin{array}{r}\text { T1 Without Prestige } \\
\text { ST }\end{array}$ & $\begin{array}{r}\text { T2 } \\
\text { (All) }\end{array}$ & T2 Without Prestige \\
ST \\
\hline Overall & 0.999 & 0.988 & 0.997 & 0.990 \\
\hline $\begin{array}{l}\text { Observer } \\
\text { A }\end{array}$ & 0.999 & 0.997 & 0.999 & 0.996 \\
\hline $\begin{array}{l}\text { Observer } \\
\text { B }\end{array}$ & 0.998 & 0.999 & 1.000 & 0.999 \\
\hline $\begin{array}{l}\text { Observer } \\
\text { C }\end{array}$ & 0.999 & 0.992 & 0.999 & 0.974 \\
\hline
\end{tabular}

Table 5. Concordance Correlation Coefficients.

\begin{tabular}{|l|r|r|}
\hline & T1 & T2 \\
\hline First Measurement (All) & 0.898 & 0.974 \\
\hline Repeat Measurement (All) & 0.911 & 0.992 \\
\hline First Measurement Without Prestige ST & 0.86 & 0.913 \\
\hline Repeat Measurement Without Prestige ST & 0.861 & 0.924 \\
\hline
\end{tabular}

lowing implantation of the titanium implants (Titanium ProDisc $C$ prototype, Discover, Bryan, and Prestige LP). In each case, the neural foramina and the canal was fully visualized at the index level and the adjacent levels on both T1 and T2 images. With the cobalt-chrome ProDisc-C device, the superior and inferior adjacent levels were fully visualized on both $\mathrm{T} 1$ and $\mathrm{T} 2$ sequences. The index level was however partially distorted and could not be visualized (Table 6). Following implantation of the Prestige ST device, significant distortion of the implanted and the adjacent levels were noted. In this case, the neural foramina and the canal could not be visualized (Figure 6).

\section{Discussion}

The goal of cervical total disc replacement is to improve patient outcome by the preservation of normal spinal motion and biomechanics with an associated reduction of adjacent segment degeneration. ${ }^{9} \mathrm{Nu}$ -
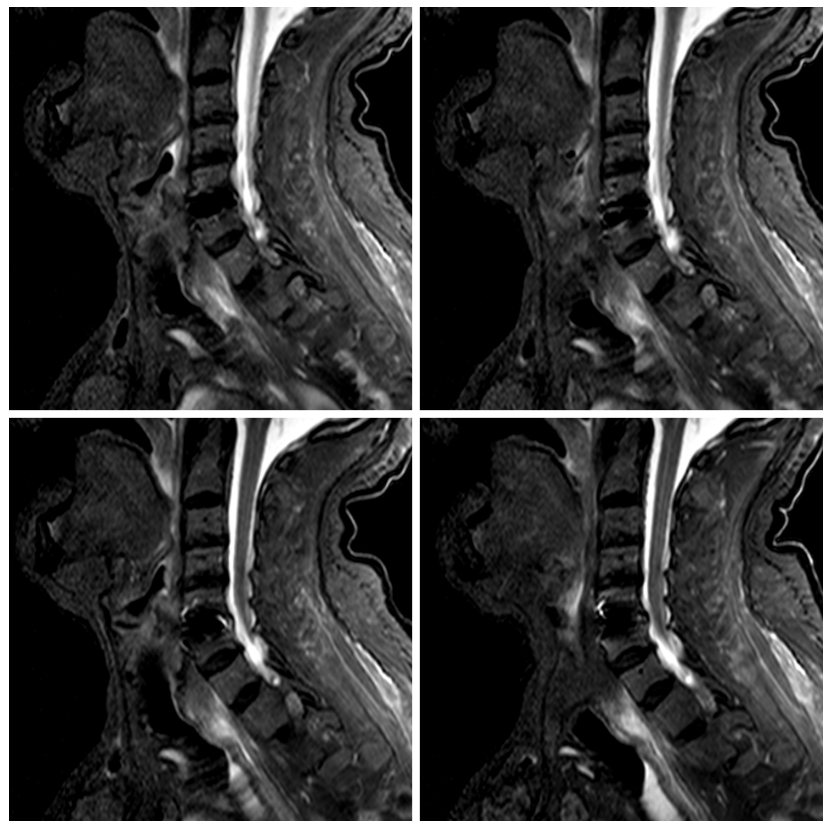

Fig. 5. Minimal artifact was seen following the implantation of the Titanium Devices; Bryan (Top Left), Discover (Top Right), Prestige LP (Lower Left), and Prodisc C Ti (Lower Right).

Table 6. Qualitative measurements by level and implant.
\begin{tabular}{|l|r|r|r|r|r|r|}
\hline Level & ProDisc-C & $\begin{array}{r}\text { ProDisc-C } \\
\text { Ti }\end{array}$ & $\begin{array}{r}\text { Prestige } \\
\text { LP }\end{array}$ & Discover & Bryan & $\begin{array}{r}\text { Prestige } \\
\text { ST }\end{array}$ \\
\hline Index & $\begin{array}{r}\text { Partially } \\
\text { Distorted }\end{array}$ & $\begin{array}{r}\text { Fully } \\
\text { Visualized }\end{array}$ & $\begin{array}{r}\text { Fully } \\
\text { Visualized }\end{array}$ & $\begin{array}{r}\text { Fully } \\
\text { Visualized }\end{array}$ & $\begin{array}{r}\text { Fully } \\
\text { Visualized }\end{array}$ & $\begin{array}{r}\text { Fully } \\
\text { Distorted }\end{array}$ \\
\hline Adjacent & $\begin{array}{r}\text { Fully } \\
\text { Visualized }\end{array}$ & $\begin{array}{r}\text { Fully } \\
\text { Visualized }\end{array}$ & $\begin{array}{r}\text { Fully } \\
\text { Visualized }\end{array}$ & $\begin{array}{r}\text { Fully } \\
\text { Visualized }\end{array}$ & $\begin{array}{r}\text { Fully } \\
\text { Visualized }\end{array}$ & $\begin{array}{r}\text { Fully } \\
\text { Distorted }\end{array}$ \\
\hline
\end{tabular}


merous biomechanical studies have demonstrated that cervical disc replacements preserve motion at the index and adjacent levels after implantation of cervical TDR..$^{9-14}$ Of even more relevance, several clinical studies have also demonstrated these same trends. ${ }^{15-17}$

While anterior cervical discectomy and fusion (ACDF) is still the most popular treatment for degenerative disc disease, cervical disc replacements have become an effective option. These devices may potentially decrease the rate of adjacent segment disease requiring revision surgery, which occurs in $2.9 \%$ of ACDF patients per year. ${ }^{18}$ Despite the potential benefit of the TDR, adjacent segment disease will continue to occur. Furthermore, in a small subgroup of the patients, issues may arise from the index level requiring radiographic evaluation.

MRI evaluation of a symptomatic patient is essential following TDR. Although post-myelogram CT scan can be used to visualize the neural canal, it results in a high radiation dose and may increase the rate of cancer especially in a young patient. ${ }^{19}$ Metallic implants also result in $\mathrm{x}$-ray scatter and can prevent the visualization of the canal. This is especially problematic given the close proximity of the metallic TDR to the neural foramina. The material properties of the

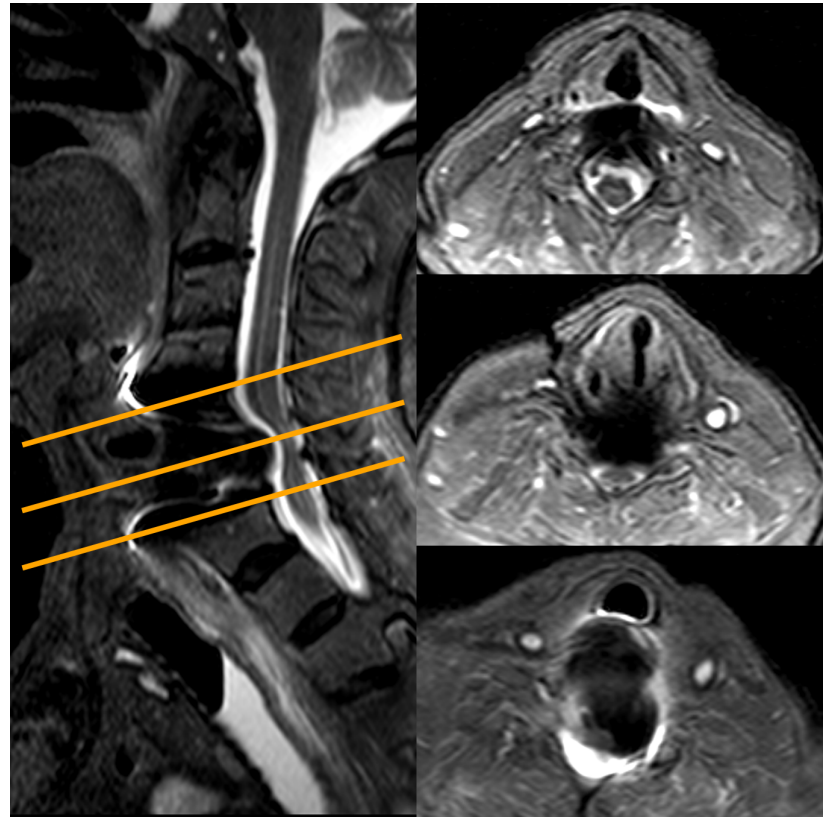

Fig. 6. Significant distortion was noted following implantation of the stainless steel Prestige ST implant; neither the index nor the adjacent levels could be assessed following implantation. implant will also affect the scatter. ${ }^{6}$

The quality of the MRI artifact and the ability to visualize the anatomic structures following TDR has previously been studied by Sekhon et. al. ${ }^{1}$ The author used a qualitative, subjective technique (Jarvik scale from 1 to 4 ) that resulted in moderate correlation between the observers (reliability ranging from 0.48 to 0.74; mean interobserver ICC was 0.57). In this study, we have clearly demonstrated a reliable and reproducible method for measuring the MRI artifact produced following implantation of artificial disc replacement.

This study was designed to quantify the amount of artifact following TDR and to evaluate the intraobserver and interobserver reliability of the measurements. Six different TDR designs were utilized and the amount of artifact was measured following implantation of each of the devices. All of the devices used were on the smaller side compared to the sizes available and fairly similar with respect to footprint with the Discover implant having the largest footprint. Larger sizes could have more artifact, but the artifact was more dependent upon the materials (and therefore weight, Table 2). The amount of artifact was highest following implantation of the Prestige ST implant, which consists of stainless steel metalon-metal bearing surface. Similar amount of artifact was measured following implantation of the four titanium devices (ProDisc-C Ti, Prestige LP, Discover, and Bryan) despite the difference in the geometry of each device.

MRI can continue to be used as the preferred technique when evaluating the cervical spine. Given this result, MRI can be used following artificial disc replacement except when a Prestige ST device has been implanted. In case of the Prestige ST, neither the adjacent nor the index levels were visualized on MRI. The visualization of the adjacent level and the index level can easily be performed following implantation of titanium devices. In case of the ProDisc-C Cobalt-Chrome implant, the adjacent segments are easily visualized where as the index level was obscured by the metal artifact. 


\section{Conclusion}

The artifact seen on the MRI scan following implantation of a total disc device was highly dependent on the material properties of the device. Qualitatively, the neural elements at both the implanted and the adjacent levels were easily visualized following implantation of a titanium device as compared to both cobalt chrome and stainless steel implant. Quantitatively, all the titanium implants resulted in similar artifact volumes. Stainless steel device produced the largest amount of artifact. Quantitative measurement of artifact volume is a reproducible and a valid technique.

\section{References}

1. Sekhon LH, Duggal N, Lynch JJ, et al. Magnetic resonance imaging clarity of the Bryan, Prodisc-C, Prestige LP, and PCM cervical arthroplasty devices. Spine. 2007;32(6):673-80.

2. Phillips FM, Garfin SR. Cervical disc replacement. Spine. 2005;30(17 Suppl):S27-33.

3. Smith HE, Wimberley DW, Vaccaro AR. Cervical arthroplasty: material properties. Neurosurgical Focus. 2004;17(3):E3.

4. Rupp R, Ebraheim NA, Savolaine ER, Jackson WT. Magnetic resonance imaging evaluation of the spine with metal implants. General safety and superior imaging with titanium. Spine. 1993;18(3):379-85.

5. Wang JC, Yu WD, Sandhu HS, Tam V, Delamarter RB. A comparison of magnetic resonance and computed tomographic image quality after the implantation of tantalum and titanium spinal instrumentation. Spine. 1998;23(15):1684-8.

6. Suh JS, Jeong EK, Shin KH, et al. Minimizing artifacts caused by metallic implants at MR imaging: experimental and clinical studies. AJR American Journal of Roentgenology. 1998;171(5):1207-13.

7. Tormanen J, Tervonen O, Koivula A, Junila J, Suramo I. Image technique optimization in MR imaging of a titanium alloy joint prosthesis. Journal of Magnetic Resonance Imaging. 1996;6(5):805-11.

8. Viano AM, Gronemeyer SA, Haliloglu M, Hoffer FA. Improved MR imaging for patients with metallic implants. Magnetic Resonance Imaging. 2000;18(3):287-95.
9. Durbhakula MM, Ghiselli G. Cervical total disc replacement, part I: rationale, biomechanics, and implant types. Orthopedic Clinics of North America. 2005;36(3):349-54.

10. Cunningham BW, Gordon JD, Dmitriev AE, $\mathrm{Hu}$ $\mathrm{N}, \mathrm{McAfee}$ PC. Biomechanical evaluation of total disc replacement arthroplasty: an in vitro human cadaveric model. Spine. 2003;28(20):S110-7.

11. DiAngelo DJ, Foley KT, Morrow BR, et al. In vitro biomechanics of cervical disc arthroplasty with the ProDisc-C total disc implant. Neurosurg Focus. 2004;17(3):44-54.

12. DiAngelo DJ, Roberston JT, Metcalf NH, McVay BJ, Davis RC. Biomechanical testing of an artificial cervical joint and an anterior cervical plate. Journal of Spinal Disorders \& Techniques.

2003;16(4):314-23.

13. Dmitriev AE, Cunningham BW, Hu N, Sell G, Vigna F, McAfee PC. Adjacent level intradiscal pressure and segmental kinematics following a cervical total disc arthroplasty: an in vitro human cadaveric model. Spine. 2005;30(10):1165-72.

14. Puttlitz CM, Rousseau MA, Xu Z, Hu S, Tay $\mathrm{BK}$, Lotz JC. Intervertebral disc replacement maintains cervical spine kinetics. Spine.

2004;29(24):2809-14.

15. Mummaneni PV, Burkus JK, Haid RW, Traynelis VC, Zdeblick TA. Clinical and radiographic analysis of cervical disc arthroplasty compared with allograft fusion: a randomized controlled clinical trial. Journal of Neurosurgery Spine.

2007;6(3):198-209.

16. Robertson JT, Metcalf NH. Long-term outcome after implantation of the Prestige I disc in an endstage indication: 4-year results from a pilot study. Neurosurgical Focus. 2004;17(3):E10.

17. Sasso RC, Smucker JD, Hacker RJ, Heller JG. Artificial disc versus fusion: a prospective, randomized study with 2-year follow-up on 99 patients. Spine. 2007;32(26):2933-40; discussion 41-2. 18. Hilibrand AS, Carlson GD, Palumbo MA, Jones PK, Bohlman HH. Radiculopathy and myelopathy at segments adjacent to the site of a previous anterior cervical arthrodesis. Journal of Bone \& Joint Surgery - American Volume. 1999;81(4):519-28.

19. Berrington de Gonzalez A, Mahesh M, Kim KP, et al. Projected cancer risks from computed tomo- 
graphic scans performed in the United States in 2007. Archives of Internal Medicine.

2009;169(22):2071-7.

\section{Disclosures}

This study was supported in part by Synthes Spine through a research grant to the institution. David Svach and Jeff Stein are paid employees for DePuy Synthes. These authors and their immediate families did not receive any additional payments or benefits. All other authors declare no relevant financial disclosures.

\section{Corresponding Author}

Nathaniel Ordway, SUNY Upstate Medical Center, 750 East Adam Street, Syracuse, NY 13201. ordwayn@upstate.edu

Published 14 July 2015.

This manuscript is generously published free of charge by ISASS, the International Society for the Advancement of Spine Surgery. Copyright ๑ 2015 ISASS. To see more or order reprints or permissions, see http://ijssurgery.com. 